\title{
Spamming in Scholarly Publishing: A Case Study
}

\author{
Marcin Kozak \\ Department of Quantitative Methods in Economics, University of Information Technology and Management in \\ Rzeszow, Sucharskiego 2, Rzeszów 35-225, Poland. E-mail: nyggus@gmail.com \\ Olesia lefremova \\ Department of Social Sciences, University of Information Technology and Management in Rzeszow, \\ Sucharskiego 2, Rzeszów 35-225, Poland. E-mail: oiefremova@wsiz.rzeszow.pl \\ James Hartley \\ School of Psychology, Keele University, Staffordshire ST5 5BG, United Kingdom. E-mail: \\ j.hartley@keele.ac.uk
}

\begin{abstract}
Spam has become an issue of concern in almost all areas where the Internet is involved, and many people today have become victims of spam from publishers and individual journals. We studied this phenomenon in the field of scholarly publishing from the perspective of a single author. We examined 1,024 such spam e-mails received by Marcin Kozak from publishers and journals over a period of 391 days, asking him to submit an article to their journal. We collected the following information: where the request came from; publishing model applied; fees charged; inclusion or not in the Directory of Open Access Journals (DOAJ); and presence or not in Beall's (2014) listing of dubious journals. Our research showed that most of the publishers that sent e-mails inviting manuscripts were (i) using the open access model, (ii) using article-processing charges to fund their journal's operations; (iii) offering very short peer-review times, (iv) on Beall's list, and (v) misrepresenting the location of their headquarters. Some years ago, a letter of invitation to submit an article to a particular journal was considered a kind of distinction. Today, e-mails inviting submissions are generally spam, something that misleads young researchers and irritates experienced ones.
\end{abstract}

\section{Introduction}

"Spam" has many faces. Depending on your country and your point of view, there are many definitions of spam and the legal regulations surrounding it. However, in this article, we shall not examine this issue from the legal perspective of

Received February 27, 2014; revised January 23, 2015; accepted January 23, 2015

(C) 2015 ASIS\&T • Published online in Wiley Online Library (wileyonlinelibrary.com). DOI: 10.1002/asi.23521 different countries. Our study is concerned with documenting the growing number of spam e-mails and the problems that they cause in scholarly publishing. Such e-mails usually contain invitations to submit articles to a new, or a recently started, journal, sometimes with tables of forthcoming contents and/or information about promotional offers. Here, we define "spam e-mail" in scholarly journals as "unsolicited bulk e-mail" sent to authors by non-bona-fide publishers and journals, and sometimes by "rogue traders." "Unsolicited" means that the recipient has not requested the message, and "bulk" that the message has been sent as part of a larger package of messages with substantially the same content.

The main players in scholarly publishing-journals and publishers-use different access models. In publishing the most common of these are (a) traditional subscription journals (based on subscriptions of the readers), (b) open access (OA), and (iii) hybrid (where chosen articles from some issues are OA). In recent years, journals using OA have been gaining popularity. OA focuses on free access to published articles for readers and a wider dissemination of knowledge. OA is funded by the authors, their home institutions, government grants, or a publisher's internal funds.

Spamming seems to be most noticeable in the OA model. Today's authors receive more and more e-mails from OA journals soliciting manuscripts for publication, as well as from publishers that publish one or more OA journals. Such advertising has become spam, and it is now a significant problem in scholarly communication. Researchers who receive these invitations often do not read them anymore. Instead, such e-mails are classified as junk (either manually or automatically). Accordingly, some important e-mails (e.g., actual invitations to write a review article) can land, by default, in the junk mail (Arun \& Bohra, 2013; 
Suryanarayanan, 2012). What was some time ago considered a distinction (an invitation to submit) is currently often considered a spam-or even a scam.

To support and sustain OA, publishers can apply different income streams, such as advertising or sponsorship revenue, subsidies and grants, volunteering help, and article processing charges (APCs) (Crow, 2009). Although spamming is not limited to just one type of income model for a journal, it is the OA journals that use APCs that are perhaps most exploited by spammers. Some of these journals are of high quality, but some others use this model only to make money and not to disseminate knowledge. Misconduct by scientific journals and publishers motivated Jeffrey Beall to carry out research on the misuse of OA. As a result of this research, Beall regularly publishes a list of potential, possible, or probable so-called "predatory" OA publishers that exploit the author-pays model (Beall, 2012a, 2014). Beall's list has since been both endorsed and challenged by several scientific authors and bloggers (Bohannon, 2013; Butler, 2013; Davis, 2013; Poynder, 2012). And, although we have used Beall's list in writing this article, this does not mean that we endorse it: In this research, we are neutral as regards the list, but we do think that our research can contribute indirectly to the discussions around it.

Spamming is a different problem from predation. To be a spammer does not mean being predatory, but being predatory does entail being a spammer. Predation relies on spamming and it can lead to various negative consequences. Many young researchers who lack deep knowledge of scholarly publishing (and are thus unable to differentiate between real and predatory journals) may get trapped by the latter. One might choose to publish in a low-quality journal, for example, because it offers both rapid reviewing and acceptance of articles followed by fast publication. Indeed, Suryanarayanan (2012) reports that, for some time now, invitations to authors to submit reviews have been sent out without any consideration of the authors' research areas.

In an extensive literature search, we were not able to find any previous studies of spamming in scholarly publishing. This article aims to fill this gap by (a) studying the level of spamming in scholarly journals from the perspective of a single author and (b) analyzing the range of services and the transparency of journals that use electronic mail to invite authors to submit scientific manuscripts.

\section{Method}

We collated all the e-mails from scientific journals and publishers that were received by Dr. Marcin Kozak (the first author) from August 6, 2012 to August 31, 2013 (i.e., 391 days). Dr. Kozak is an interdisciplinary researcher, working in and among the fields of agriculture, biology, statistics, information sciences, and social sciences. Four active e-mail accountswere considered: nyggus@gmail.com; m.kozak@ omega.sggw.waw.pl (alias marcin.kozak@omega.wsiz .rzeszow.pl); mkozak@wsiz.rzeszow.pl; and marcin_kozak @sggw.pl. The first one (nyggus@gmail.com) and the second one (m.kozak@omega.sggw.waw.pl) were used most often as the corresponding e-mail in articles authored and coauthored by Dr. Kozak. The third one (mkozak@ wsiz.rzeszow.pl) was used just once in this way, whereas the last one (marcin_kozak@sggw.pl) was never used as a corresponding e-mail address in scientific articles.

We analyzed the journals and publishers that sent these e-mails, using the information included in the e-mail body, the corresponding web pages of the journal/publisher, and other sources (see following).

For both journals and publishers, we studied the following elements:

- The e-mail account to which the e-mail was sent,

- whether or not the e-mail address from which the letter was sent was from a public domain, such as gmail, yahoo, rediffmail, etc., or from an institutional domain. Personal domains were included in the first group of public domains,

- whether or not the beginning of the letter was personalized by using the name of the addressee ("Marcin Kozak," "Dr. Kozak," or "M. Kozak" and the like),

— the web page of the journals/publishers and whether or not they were working,

- the country of origin, obtained from three sources:

web page of the journal or publisher

web page http://who.is/whois

web page http://www.ip-adress.com/,

— information about article processing charges, if applied,

- maximum peer-review time promised in the letter/web page,

- access model applied (e.g., OA, Subscription, Hybrid, etc.),

- inclusion in the Directory of Open Access Journals (DOAJ) (DOAJ, 2014), and

— inclusion in Beall's list (Beall, 2012b, 2014).

The additional following elements were also studied, particularly for journals:

— information about editorial board (yes/no),

— ISSN provided (yes/no),

and particularly for publishers:

— number of published journals; source of information: e-mail or web page of the publisher.

All of the analyses were carried out in September 2013.

\section{Results and Discussion}

Table 1 summarizes the general information obtained. A total of 1,024 e-mails were collected during the 391 days, with a mean of 2.61 per day. In total, 796 of these (mean $=2.0$ per day; $78 \%$ of all e-mails) were sent from persons representing journals and 228 (mean $=0.6$ per day; $22 \%$ of all e-mails) from persons representing publishers. Many of these e-mails were sent from the same journals and publishers. The 796 e-mails were sent from 277 journals (mean $=2.9$ per journal). The maximum number of e-mails 
TABLE 1. General information about e-mails received from journals and publishers.

\begin{tabular}{lcc}
\hline Parameter & Journals & Publishers \\
\hline Total no. of entities & 277 & 57 \\
Total no. of e-mails & 796 & 228 \\
Mean no. of e-mails per day & 2.0 & 0.6 \\
Mean no. of e-mails per entity & 2.87 & 4 \\
Maximum no. of e-mails sent by one entity & 24 & 40 \\
Receiver's e-mail address & & \\
nyggus@gmail.com & $89.7 \%(714)$ & $79.4 \%(181)$ \\
m.kozak@omega.sggw.waw.pl & $7.4 \%(59)$ & $18.9 \%(43)$ \\
mkozak@wsiz.rzeszow.pl & $2.9 \%(23)$ & $0.9 \%(2)$ \\
marcin_kozak@ sggw.pl & \multicolumn{1}{c}{$-12 \%(2)$} \\
Apparent domain type of the e-mail account & $80.2 \%(638)$ & $57.9 \%(132)$ \\
Institutional & $19.9 \%(158)$ & $42.1 \%(96)$ \\
Public & & \\
Personalization of the e-mail & $82.5 \%(657)$ & $88.6 \%(202)$ \\
No & $17.3 \%(138)$ & $11.4 \%(26)$ \\
Yes & $0.1 \%(1)$ & - \\
Wrong name & &
\end{tabular}

from one journal was 24,15 journals sent at least 10 e-mails, and 142 journals sent more than one e-mail during the period studied.

When considering the four e-mail accounts, we found that most e-mails from journals and publishers were sent to nyggus@gmail.com. This suggests that the main source of the e-mail addresses were articles published in scientific journals and not those in personal web pages at university sites.

Journals and publishers that sent e-mails were classified based on the access model applied, as (1) OA, (2) traditional subscription access, and (3) hybrid (a combination of OA and subscription model). Some journals and publishers had no articles available and some had dead links to their articles, so it was not possible to determine the access policy they used.

Publishers were additionally evaluated in terms of number of journals they published. One of the publishers published 371 journals and another one 300; six publishers published more than 100 journals. There was one publisher that published just one journal. Interestingly, the link"Journals" - on its web page directed the reader to Elsevier's web page, although Elsevier and this publisher had nothing in common.

E-mails were apparently sent mainly from institutional domains (58\%; 132 e-mails), but 96 e-mails (42\%) were sent from public domains. Noticeably, Beall includes the domain part of contact e-mail accounts as one of the criteria for determining the predatory nature of publishers (Beall, 2012b).

\section{Headquarters' Location}

We used three methods to determine the location of the publishers' headquarters: (i) from the web page of the
TABLE 2. The top five countries in terms of (i) the number of entities and (ii) the location of their headquarters. Top: Information from the web pages; Middle: Information from the WHOIS webpage; Bottom: Information from IP addresses.

\begin{tabular}{lcc}
\hline Top five countries* & Journals & Publishers \\
\hline Info from the web page of entity & & \\
India & $10.8 \%(30)$ & $26.3 \%(15)$ \\
United States & $8.6 \%(24)$ & $8.7 \%(5)$ \\
Nigeria & $6.8 \%(19)$ & $3.5 \%(2)$ \\
United States/China & $6.5 \%(18)$ & - \\
United States/Nigeria & $6.1 \%(17)$ & - \\
Iran & - & $3.5 \%(2)$ \\
Canada & - & $3.5 \%(2)$ \\
Info from WHO.IS web page & $26.3 \%(73)$ & $14.0 \%(8)$ \\
Nigeria & $15.8 \%(44)$ & $28.0 \%(16)$ \\
India & $12.6 \%(35)$ & - \\
China & $10.1 \%(28)$ & $17.5 \%(10)$ \\
United States & $9.3 \%(26)$ & $8.7 \%(5)$ \\
Hidden by WHO.IS & - & \\
Canada & & $64.9 \%(37)$ \\
Info from IP address & $75.4 \%(209)$ & - \\
United States & $4.3 \%(12)$ & $8.7 \%(5)$ \\
China & $3.2 \%(9)$ & $5.2 \%(3)$ \\
India & $3.2 \%(9)$ & - \\
Singapore & $3.2 \%(9)$ & $3.5 \%(2)$ \\
United Kingdom & - & \\
Virgin Islands & - & \\
Canada & & \\
\hline
\end{tabular}

Note. ${ }^{*}$ There are different countries in each column of the table because only the top five countries for both journals and publishers are presented.

journal; (ii) http://who.is/whois web page; and (iii) checking the Internet Protocol (IP) address. Table 2 shows the results.

The top section of Table 2 shows the top five countries for the journals based on the information obtained from the web page of the journal. As can be seen, the most frequent locations were India, the United States, and Nigeria. It was not possible to determine the locations of four journals, given that we were unable to read their web pages.

The top five countries for publishers are also shown in Table 2. Here, it can be seen, from the information obtained from web pages of publishers, that $30 \%$ (17 publishers) did not reveal their location. The most frequent countries similarly to journals were India, the United States, Nigeria, Iran, and Canada. One web page was created in Google Sites service and it was not possible to determine its location.

The middle section of Table 2 shows the results of an analysis similar to that made by Bohannon (2013). He determined the location of journals by using various methods, one of which was based on the website http://who.is/whois. This is a useful procedure because many journals do not state their headquarters and indeed they often misrepresent their location in order to attract more authors (Beall, 2012b). The results obtained from http://who.is/whois were, in fact, quite different from those reported on the web pages of journals (Table 2, top section). Using http://who.is/whois, we found (Table 2, middle section) that 73 journals $(26 \%)$ were from Nigeria, 44 (16\%) from India, and 35 (13\%) from 
TABLE 3. Cross-relationships of methods used to determine country locations. Method key: 1 = web page claim, $2=$ WHO.IS, $3=$ IP address.

\begin{tabular}{lcccc}
\hline Method & $1 \& 2$ & $1 \& 3$ & $2 \& 3$ & $1,2 \& 3$ \\
\hline Journals & $24 \%(66)$ & $11 \%(30)$ & $18 \%(50)$ & $8 \%(22)$ \\
Publishers & $37 \%(22)$ & $14 \%(8)$ & $25 \%(14)$ & $12 \%(7)$ \\
\hline
\end{tabular}

China. Only approximately $36 \%$ (i.e., 28 of the 78 journals that claimed to originate from the United States) were actually located there. Twenty-six journals used the WHO.IS service so that readers cannot determine where the server of the domain is located.

For publishers based on the analysis from the web page $\mathrm{http}: / /$ who.is/whois, the results were similar to those of journals, with the most frequent countries being India, the United States, and Nigeria. As was with journals, nine publishers used the Privacy Protect function in WHO.IS and their location appeared to be in Australia. Clearly, WHO.IS is not a reliable method for determining the location of journals and publishers.

The bottom section of Table 2 shows the results of yet another method of determining the location of journals, based on checking the IP addresses of the servers of their web pages. This was done using the web page http:// www.ip-adress.com/. According to this analysis, 209 journals $(75 \%)$ had their server located in the United States, 12 (4\%) in China, and nine (3\%) each in the UK, Singapore, and India. It is widely known, of course, that the location of a server does not have to reflect the location of headquarters.

As for the publishers, based on IP checking, 37 (65\%) had their servers located in the United States, five in India, and three each in Singapore and the Virgin Islands.

To examine the comparability of the three methods used, we made a cross-relationships analysis of the data obtained from web pages of journals, WHO.IS, and IP address check. The results (Table 3 ) indicated that there were only minor differences between journals and publishers here.

Information about the location of the journals from their web pages was confirmed by WHO.IS in $24 \%$ of the cases and $11 \%$ by means of the IP address check. The information on localization obtained from all three methods only matched for only $8 \%$ of the journals. This shows that finding the location of a journal sending e-mails can be very difficult and, in many cases, impossible.

The locations of the headquarters provided by the publishers (Method 1) were confirmed by WHO.IS (Method 2) in only $37 \%$ of the cases: The IP address check (Method 3) showed only a $14 \%$ match with the information from the web pages of the publishers. The same location only came up in $12 \%$ of the cases when all three methods were used. Thus, as was the case with journals, there was considerable difficulty in determining the real locations of publishers.

\section{Access Models}

Following the analyses of the publishers and journals that sent e-mails to Dr. Kozak, three main access models were
TABLE 4. Access policies of journals and publishers.

\begin{tabular}{lcc}
\hline Parameter & Journals (277) & Publishers (57) \\
\hline OA & $73.7 \%(204)$ & $59.7 \%(34)$ \\
Paid subscription & $6.9 \%(19)$ & $14.0 \%(8)$ \\
Hybrid & $3.6 \%(10)$ & $1.8 \%(1)$ \\
Registration required (free) & $0.7 \%(2)$ & $5.3 \%(3)$ \\
No articles and no info & $15.2 \%(42)$ & $19.3 \%(11)$ \\
\hline
\end{tabular}

distinguished: OA, Subscription, and Hybrid (a combination of both). Some journals and publishers provided no information about the model they used and some did not have any articles available and were thus analyzed separately. Table 4 summarizes the findings about access model for journals and publishers.

Of the 277 journals that sent e-mails, 204 (74\%) used the OA model and indeed readers could download the articles free of charge without any need for registration. Another 24 (9\%) claimed to use OA, but there were no such articles on their web pages; it might be possible that these were new journals, with no articles yet published. Ten (4\%) journals provided only error messages when we searched for articles published by them. Only 19 (7\%) journals used the paid subscription model, where readers pay for the right to read an article.

Access models applied by publishers were the same as those applied by journals. Most publishers $(34 ; 60 \%)$ used $\mathrm{OA}$, so articles published in their journals were freely available for everybody. Eight publishers used a subscription model, whereby readers pay to read articles. Seven publishers had no articles available for readers and three required registration to gain access to published content.

\section{$D O A J$}

The next piece of information that we collected was whether or not a journal or publisher that claimed to be OA was included in the DOAJ (DOAJ, 2014). This is an online directory that indexes approximately $9,000 \mathrm{OA}$ journals that meet the requirements listed in the selection criteria of the organization concerned with coverage, access, quality, and period of publication. From our analysis, it appeared that only $57(27 \%)$ of the OA journals present in our research were indexed in the DOAJ.

Most of the publishers, as with the journals, supported OA and could also be indexed in the DOAJ (DOAJ, 2014). In general, however, not all the journals of a publisher have to be included in DOAJ for the publisher to be included. Thus, for the purpose of this research, if at least one journal was on the DOAJ list, the publisher of that journal was included as a DOAJ member. Most of the OA publishers $(27 ; 79 \%)$ were non-DOAJ members and only seven $(21 \%)$ OA publishers were indexed in the DOAJ.

\section{Income Models}

To cover the cost of their operations, journals and publishers can use different income models, such as 
subscriptions from readers and libraries, institutional subsidy, APCs, advertising, and sponsorship revenues and, in some cases, a combination of some of these. In order to examine the transparency of the journals and publishers that sent e-mails, we further analyzed the data to see whether any information was provided about APCs (if such applied) on the web page or in the e-mail sent. From this research, it appeared that, in some cases, the information about charges was readily available in an e-mail, and that, most of the time, it could also be found under the link "Authors' Guidelines" or "Fees and Charges" on the journals' web pages. Table 5 presents the results for these journals and publishers. Overall, 202 journals $(73 \%)$ provided clear information on charges and fees, but 46 (17\%) provided no such information about charges and fees. Here, of course, "no information" does not mean there are no fees and charges. The web pages of 12 journals (4\%) were not working (this was checked several times), so that the information on charges was not available.

Five journals offered promotions (e.g., publishing free of charge until the end of a particular month), and information about waiving the handling fees under special circumstances was posted on the web pages of some journals. Usually, charges and fees were lower for authors from developing countries.

Of the 57 publishers, $44(80 \%)$ had clear information about charges and fees, but nine $(20 \%)$ provided no such information. Only three publishers offered a free of charge publication of articles; another one had a special offer, with free publication for manuscripts submitted until the end of July 2013.

Our study is thus dominated by journals using OA policies. Of all journals analyzed (277 journals), 96\% offered publishing for a fee. Of 212 journals that use OA, 97\% charged for publication (excluding special offers of free publication). Furthermore, although it is known that most OA journals do not charge APCs and have different sources of income (Kozak \& Hartley, 2013; Walters \& Linvill, 2011), journals from our study used APCs to a much greater extent than other sources of revenue. This is quite a different situation from that reported by Kozak and Hartley (2013), who studied the whole of the DOAJ database. In their report, only $28 \%$ of over 9,000 OA journals included in DOAJ

TABLE 5. Information about fees for journals and publishers.

\begin{tabular}{lcc}
\hline Parameter & Journals (277) & Publishers (57) \\
\hline Information about fees & & \\
Yes & $72.9 \%(202)$ & $77.2 \%(44)$ \\
No information & $16.6 \%(46)$ & $15.8 \%(9)$ \\
Free of charge & $4.3 \%(12)$ & $5.3 \%(3)$ \\
N/A & $4.3 \%(12)$ & - \\
Promotions & $1.8 \%(5)$ & $1.8 \%(1)$ \\
\hline
\end{tabular}

Note. N/A, not available. charged for publication. This share, of course, differed from discipline to discipline, with the highest share in the sciences $(43 \%)$ and lowest in the humanities (4\%) and the arts $(0 \%)$. This difference in the findings between the present study and that of Kozak and Hartley (2013) suggests that it was mainly those OA journals that charged for publication that sent e-mail invitations to authors to submit an article. These OA journals (in which costs are not sustained by APCs) appear to have different ways of advertising. This phenomenon calls for further studies on the advertising strategies of scientific journals. Of the $64 \mathrm{OA}$ journals from our analysis that are on the DOAJ list, only 4 offered publishing free of charge.

\section{Beall's List}

Another element that we considered in our analysis was whether or not the journals and publishers that we studied were present in Beall's list (Beall, 2014). Only publishers and journals that use $\mathrm{OA}$ are listed here, and thus this analysis refers only to those journals following this access policy. As noted earlier, Beall created a list of potential, possible, or probable predatory scholarly OA publishers and individual journals. The criteria for adding a publisher or an individual journal to the list are described in Beall (2012b), and the list is updated weekly. Beall defines predatory publishers as those who unprofessionally exploit the author-pays model for their own profit (Beall, 2012a). Beall looks for deception and lack of transparency (Poynder, 2012).

We found that $212(77 \%)$ of the 277 journals that we studied were present in Beall's list at the time of the analysis (mid-September 2013). Seventy-five (27\%) of the journals that were on Beall's list also appeared in the DOAJ database. Whether or not Beall's criteria are too harsh or the DOAJ not strict enough is a matter for further study.

Forty publishers $(70 \%)$ were included in Beall's list of potential, possible, or probable predatory scholarly OA publishers. Seventeen publishers $(30 \%)$ were not present on this list.

The goal of predatory publishers that use OA is to exploit the OA model of charging a fee without providing all the expected publishing services (Beall, 2012a). Such services include (a) scientific quality, which results mainly from the authors' work, but also from editorial and peer-review standards, and (b) technical quality, which results from good copyediting and high typographical standards. Furthermore, the OA model implies that all articles will be disseminated effectively: All articles should be free to access, and they should all be available in repositories and/or databases that can be searched by any reader. Predatory journals seldom provide all these services, but they do use spamming to attract inexperienced authors to submit articles and pay money.

Not wishing to enter this discussion, we simply recorded whether or not the publishers of the journals that we studied were included in Beall's list. 
TABLE 6. Peer-review time reported by journals and publishers in the present study.

\begin{tabular}{lcc}
\hline Parameter & Journals (277) & Publishers (57) \\
\hline Peer-review time & & \\
3 days & - & $1.8 \%(1)$ \\
1 week & $2.5 \%(7)$ & $12.0 \%(7)$ \\
2 weeks & $7.9 \%(22)$ & $14.0 \%(8)$ \\
3 weeks & $22.0 \%(61)$ & $14.0 \%(8)$ \\
4 weeks & $26.7 \%(74)$ & $12.3 \%(7)$ \\
8-16 weeks & $1.1 \%(3)$ & $1.8 \%(1)$ \\
Yes (no period defined) & $22.4 \%(62)$ & $26.3 \%(15)$ \\
No info + N/A (not available) & $11.9 \%(33)$ & $15.8 \%(9)$ \\
\hline
\end{tabular}

\section{The Promise of Fast Peer Review}

Claiming effective article dissemination through free access is not the only thing that OA journals use to attract possible authors. Another one is a faster peer-review process. This is attractive simply because normal publication processes these days can be extremely time-consuming. Arun and Bohra (2013), for example, reported a situation in which it took 4 years from the submission of an article to publication. The time spent on peer review often makes a significant contribution to this problem. According to Ware (2008), authors are very demanding when it comes to peerreview times.

Approximately two thirds of the respondents in Ware's study (of over 3,000 authors) would be happy with 4 weeks or less for peer review; only $9 \%$ would accept more than 24 weeks. In Ware's study, the average review time authors reported was approximately 11 weeks. Table 6 presents the results from our study, where over two thirds $(67 \%)$ of our journals offered peer-review times of 4 weeks or less. The longest peer-review period in the studied journals was 16 weeks and the shortest was 1 week.

One of our publishers offered potential authors a review time of 3 days, and peer-review times between 1 and 4 weeks were offered by the majority $(30 ; 53 \%)$. Nine did not mention peer-review processes.

\section{Editorial Boards}

We checked separately our analyzed journals to see whether any information was provided about their editorial boards. As is well known, the editorial board manages and ensures the validity of the content published in their journals. In this study, $234(85 \%)$ of the journals provided information about the members of their editorial boards. However, no such information was given by 35 journals (13\%), and the presence or absence of this information could not be obtained for eight journals owing to the fact that their the web pages were inactive. Unfortunately, we are unable to comment further on these data, given that analyzing editorial boards was not part of our brief.

\section{Matching the Journals to the Recipients' Field of Expertise}

We did check, however, whether or not the journals that invited Dr. Kozak to submit were appropriate for him to receive. Although this was not easy to do, because Dr. Kozak is an interdisciplinary researcher, at least $30 \%$ of the journals (such as medical, pharmaceutical, or physics) were judged to lie outside his sphere of interests. This confirms Arun and Bohra's (2013) statement describing potential reviewers searched for by OA journals with low reputations: "One need not be an expert in the journal's subject area. In many cases a researcher from one background may be asked to contribute or review a manuscript in completely unrelated field" (p. 881).

\section{Conclusions}

We have deliberately not provided the names of any journals and publishers in this article. Basically, the overall characteristics of the journals and publishers that we studied that sent spam e-mails were as follows:

- Most used the OA model (74\% of journals and $60 \%$ of publishers).

- Most of the journals and publishers were funded by APCs.

- The average time claimed for peer review was 4 weeks or less.

- Many journals and publishers gave no-or falseinformation concerning where they were based.

- Some sent as many as 40 e-mails during the period of our study.

- The layout and some parts of the letters from many publishers were the same.

- A number of the journals studied had only a few articles available for readers to see in advance, some with errors or mistakes.

- More than $70 \%$ of the publishers were present in Beall's list.

- In 75 cases, the journals present in Beall's list were also indexed in DOAJ.

- India, the United States, and Nigeria were the most frequent countries when it came to locating the headquarters of such journals and publishers.

Spam can be more harmful in scholarly publishing than it is in other areas. Researchers not only have to read it, but they also need to decide which particular journals and which publishers are predatory and which are legitimate.

Some time ago, receiving an invitation to submit an article to a particular journal was considered a mark of distinction, evidence of recognition. These days, receiving e-mails inviting the recipient to submit an article can be considered a kind of spam, something that irritates rather than flatters. Of course, no one is claiming that all publishers using APCs are guilty. But what we do claim is that this model provides an opportunity for people to be exploited by others who see easy money in scholarly publishing. 


\section{Acknowledgments}

We are indebted to two anonymous referees for their insightful comments on the first drafts of this manuscript. In addition, it is worth noting that Dr. Kozak is currently receiving many more such e-mails from journals and publishers than reported in this present study. Unfortunately, since completing this report, these e-mails have been binned.

\section{References}

Arun, W.A., \& Bohra, P. (2013). Where are our journals heading? Current Science, 105(7), 881.

Beall, J. (2012a). Predatory publishers are corrupting open access. Nature, 489(7415), 179.

Beall, J. (2012b). Scholarly Open Access. Retrieved from http:// scholarlyoa.com/2012/11/30/criteria-for-determining-predatory-openaccess-publishers-2nd-edition/

Beall, J. (2014). Scholarly Open Access. Retrieved from http:// scholarlyoa.com/publishers

Bohannon, J. (2013). Who's afraid of peer review? Science, 342(6154), 60-65.

Butler, D. (2013). Investigating journals: The dark side of publishing. Nature, 495(7442), 433-435.
Crow, R. (2009). Income models for Open Access: An overview of current practice. Scholarly Publishing and Academic Resources Coalition, Washington. Retrieved from http://www.sparc.arl.org/resources/papersguides/oa-income-models

Davis, P. (2013). Open Access "sting" reveals deception, missed opportunities. The scholarly kitchen, October 4, 2013. Retrieved from http:// scholarlykitchen.sspnet.org/2013/10/04/open-access-sting-revealsdeception-missed-opportunities/

DOAJ. (2014). Directory of Open Access Journals. Retrieved from http:// doaj.org

Kozak, M., \& Hartley, J. (2013). Publication fees for open access journals: Different disciplines-Different methods. Journal of the American Society for Information Science and Technology, 64(12), 2591-2594.

Poynder, R. (2012). The OA interviews: Jeffrey Beall, University of Colorado Denver. Retrieved from http://poynder.blogspot.co.uk/2012/07/oainterviews-jeffrey-beall-university.html

Suryanarayanan, T.S. (2012). Peer review or mere formality? Current Science, 103(8), 25.

Walters, W., \& Linvill, A.C. (2011). Characteristics of Open Access Journals in Six Subject Areas,s. College \& Research Libraries, 72(4), 372392.

Ware, M. (2008). Peer review: Benefits, perceptions and alternatives. London: Publishing Research Consortium. 